\title{
Double-blind evaluation of clonazepam on periodic leg movements in sleep
}

\author{
RON PELED, PERETZ LAVIE \\ From the Sleep Laboratory, Faculty of Medicine, Technion-Israel Institute of Technology, Haifa, Israel
}

SUMMARY Treatment with clonazepam was studied in a group of 20 patients suffering from periodic movements in sleep, in a double-blind parallel group design. Eleven complained of excessive daytime sleepiness, and nine complained of insomnia. Ten patients received clonazepam, and 10 received placebo, over a period of 1 month. Clonazepam $(0.5-2 \mathrm{mg}$ per night) proved to be an effective treatment of periodic movements in sleep. Polysomnographic recordings demonstrated a significant decrease in the number of leg movements and a significant improvement in sleep parameters in the clonazepam group as compared with placebo. Subjective responses to treatment corroborated the sleep laboratory findings.

Periodic movements in sleep are stereotyped, repetitive movements of the legs that occur primarily in non-REM (NREM) sleep. ${ }^{1}$ These movements were first described in modern times by Symonds in $1953,{ }^{2}$ and were first recorded polygraphically by Lugaresi et al in $1966 .^{3}$ They can be associated with either insomnia or hypersomnia. ${ }^{14}$ Sleep, in insomniacs with periodic movements in sleep, was found to be more fragmented than in hypersomniacs with the same condition. ${ }^{56}$

We have recently demonstrated in an open study the beneficial effect of clonazepam in the treatment of periodic movements in sleep. ${ }^{7}$ In order to confirm these results and to determine the range of effective dosages, we performed a double-blind study with clonazepam.

\section{Patients and methods}

Twenty consecutive periodic movements in sleep patients, 12 men (age range, 30-63 years) and eight women (age range, 45-70 years) participated. Eleven complained of excessive daytime sleepiness (EDS group) and nine complained of poor nocturnal sleep (insomnia group). In the insomnia group, three patients also suffered from restless legs syndrome (RLS). ${ }^{1}$ Clinical evaluation consisted of a detailed

Address for reprint requests: Peretz Lavie, Sleep Laboratory, Faculty of Medicine, Technion-Israel Institute of Technology, Haifa, Israel.

Received 17 February 1987 and in revised form 27 May 1987. Accepted 1 June 1987. sleep questionnaire, medical history, physical and neurological examinations. In the EDS group, one patient had diabetes mellitus, and two others showed bilateral mild pyramidal signs of unexplained origin. The remaining patients had no health problems. The diagnosis of periodic movements in sleep was established by conventional whole-night polysomnographic recordings including EEG, EOG, EMG, ECG, respiration, and bilateral leg movements recorded by accelerometers. Patients with sleep apnoea or narcolepsy were excluded. Leg movements were diagnosed and scored according to Coleman et al's criteria. ${ }^{4}$

\section{Treatment}

Immediately after the laboratory diagnosis of periodic movements in sleep, patients were randomly assigned to one of two treatment groups. The first group of 10 patients (six EDS and four insomniacs) received an initial dose of $1 \mathrm{mg}$ clonazepam taken 30 minutes before bedtime, and the second group (six EDS and four insomniacs) received identical placebo tablets, in a double-blind procedure. At the end of each of the 4 weeks, patients reported their subjective response, and accordingly dosage was adjusted in $0.5-1 \mathrm{mg}$ steps. Adjustment was discontinued once the patient reported on a good subjective response. Every week patients were recorded for 1 night in the sleep laboratory. Thus, for every patient there were 5 laboratory nights, a baseline and four treatment recordings. Sleep parameters were scored according to Rechtschaffen and Kales. ${ }^{8}$

The following hypnographic parameters were used to evaluate the effects of treatment: (a) Movement index: The number of leg movements per hour of sleep, (b) Arousal index: The number of leg movements with arousals per hour of sleep, (c) Sleep Latency: The time, measured in minutes, from "lights out" to the appearance of 5 continuous minutes 
of sleep stage 2, (d) Total sleep time: The amount of actual sleep tine, measured in hours, (e) Sleep efficiency: The ratio of sleep time to time in bed.

\section{Results}

\section{Pretreatment polysomnographic findings}

Pretreatment hypnographic parameters were compared between the EDS and insomnia patients (table 1). As expected, insomniacs had more difficulty in falling asleep, expressed by a longer sleep latency. The EDS patients slept longer and their sleep was less fragmented; this is evident from their higher total sleep time and sleep efficiency indices. The two groups had similar amounts of leg movements per hour of sleep, and similar amounts of leg movements plus arousals.

\section{Subjective effects of treatment}

Of the 10 patients receiving clonazepam, seven (three EDS and four insomniacs) reported marked improvement of their symptoms. The effective dosage of clonazepam was in the range of $0.5-2 \mathrm{mg}$ per night: one patient received $0.5 \mathrm{mg}$, four received $1 \mathrm{mg}$, and two received $2 \mathrm{mg}$. Of the remaining three (all EDS) one claimed no change, one complained of increased somnolence, and one stopped taking the drug after about 2 weeks, complaining of marked dizziness. In the placebo group, eight patients reported no effect at all, one felt minor improvement, and one experienced marked improvement.

\section{Objective response to treatment}

Polyhypnographic data of the nine patients (five EDS and four insomniacs) receiving clonazepam, showed marked improvement of their sleep parameters (table 2). There was shortening of sleep latency, an increase in total sleep time and in sleep efficiency index, and a decrease in the number of leg movements per hour of sleep, particularly of those associated with arousals. All these changes were statistically significant (paired $t$ tests).

The 10 patients (six EDS and four insomniacs) receiving placebo did not show any change in their sleep parameters (table 2).
Table 1 Pretreatment nocturnal sleep data

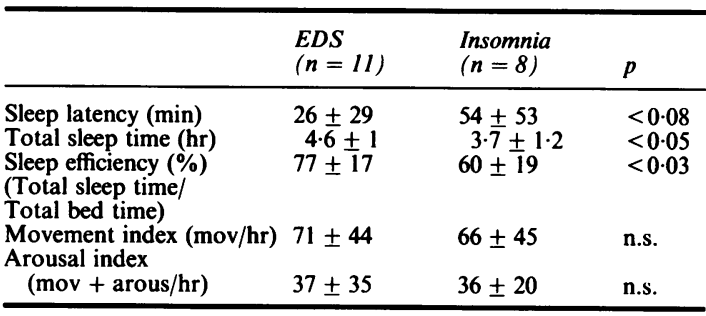

Responding patients continued taking clonazepam after the conclusion of the study. The patients who had received the placebo were then prescribed the drug, following the same drug adjustment procedure as before. The mean follow-up period so far is $10.5 \pm 3$ months. Of the 20 patients who participated in the study 17 benefited from the drug and continue to take it; three take $0.5 \mathrm{mg}, 10$ take $1 \mathrm{mg}$, and four take $2 \mathrm{mg}$ per night.

\section{Discussion}

Our present data in untreated patients with periodic movements in sleep confirmed previous findings ${ }^{5-7}$ that sleep is more disrupted in periodic movements in sleep patients complaining of insomnia as compared $\mathrm{\alpha}$ with those suffering from EDS. Insomniacs showed longer latency to consolidated sleep, reduced total sleep time, more wake time after sleep onset and consequently lower sleep efficiency indices. Examination of periodic movements in sleep parameters shows that patients complaining of insomnia and EDS do not differ from each other with regard to the number of movements per hour of sleep, nor with regard to the number of periodic movements in sleep associated with arousals. These findings may suggest that the difference in the symptomatology between the two groups may reflect individual differences in response to the same sleep disturbing stimuli.

The present results confirm our previous experience with clonazepam in treating both EDS insomniac and periodic movements in sleep patients. ${ }^{7}$ although clonazepam is the most widely prescribed

Table 2 Effect of clonazepam treatment vs. placebo on sleep parameters (all patients)

\begin{tabular}{|c|c|c|c|c|c|c|}
\hline & \multicolumn{3}{|c|}{ Clonazepam $(n=9)$} & \multicolumn{3}{|c|}{ Placebo $(n=10)$} \\
\hline & $\begin{array}{l}\text { Before } \\
\text { treatment }\end{array}$ & $\begin{array}{l}\text { After } \\
\text { treatment }\end{array}$ & $p$ & $\begin{array}{l}\text { Before } \\
\text { treatment }\end{array}$ & $\begin{array}{l}\text { After } \\
\text { treatment }\end{array}$ & $p$ \\
\hline $\begin{array}{l}\text { Sleep latency (min) } \\
\text { Total sleep time }(\mathrm{hrs}) \\
\text { Sleep Efficiency }(\%) \\
\text { Movement index }(\mathrm{mov} / \mathrm{hr}) \\
\text { Arousal index } \\
\quad(\mathrm{mov}+\text { arous } / \mathrm{hr})\end{array}$ & $\begin{array}{l}42( \pm 41) \\
3 \cdot 7( \pm 0 \cdot 9) \\
63( \pm 19) \\
60( \pm 30) \\
32( \pm 22)\end{array}$ & $\begin{array}{l}14( \pm 10) \\
5( \pm 0 \cdot 8) \\
80( \pm 11) \\
34( \pm 24) \\
13( \pm 6)\end{array}$ & $\begin{array}{l}<0.02 \\
<0.0002 \\
<0.0001 \\
<0.005 \\
<0.017\end{array}$ & $\begin{array}{l}33( \pm 46) \\
4 \cdot 7( \pm 1 \cdot 2) \\
76( \pm 18) \\
77( \pm 49) \\
41( \pm 34)\end{array}$ & $\begin{array}{l}33( \pm 25) \\
4 \cdot 3( \pm 1 \cdot 0) \\
72( \pm 12) \\
73( \pm 62) \\
48( \pm 47)\end{array}$ & $\begin{array}{l}\text { ns } \\
\text { ns } \\
\text { ns } \\
\text { ns } \\
\text { ns }\end{array}$ \\
\hline
\end{tabular}


treatment $^{4710-15}$ some authors ${ }^{913}$ have expressed doubts as to its efficacy, remarking on its variable effect, and loss of effectiveness during long-term usage. Improvement was claimed only in insomnia patients, and sometimes this was solely attributed to placebo effect, or to sedative properties. In the present study, clonazepam was found to be very effective both by subjective and objective criteria. Clonazepam significantly decreased the number of leg movements per hour of sleep, particularly in leg movements followed by arousals, and improved sleep parameters. Notwithstanding, clonazepam almost completely suppressed periodic movements in sleep occurring at sleep onset. In seven of the eight patients in the drug group who showed periodic movements in sleep within 10 minutes from sleep onset before treatment, there was a marked delay in the first appearance of periodic movements in sleep after treatment. This may indicate that clonazepam has a direct effect on the leg movements themselves rather than an unspecific sedative effect suggested by others. Possibly, failure, or only partial success of treatment with clonazepam reported by others, was due to dosage difficulties. Based on our experience with clonazepam, we believe that dosage adjustment is crucial. Each patient warrants individual dose adjustment, since insufficient dosage is ineffective, and excessive dosage may cause exacerbation of daytime tiredness and drowsiness. The present study was designed in such a way that the dosage was adjusted weekly according to each participant's requirements. This procedure proved to be most effective.

A point of interest is the finding that effective treatment does not require a complete suppression of all leg movements. For the entire drug group the total number of leg movements was reduced to about half, and the number of leg movements associated with arousals to about one third. This may indicate that the significant factor in determining the degree of sleep disruption is the number of leg movements associated with arousal, rather than the total number of movements per se.

We thank Hoffman-La Roche for supporting the study, and the staff of the Technion Sleep Laboratory for their invaluable help.

\section{References}

1 Diagnostic classification of sleep and arousal disorders (prepared by the Sleep Disorders Classification Committee, HP Roffwarg, Chairman). Sleep 1979;2: 42-45, 70-71.

2 Symonds CP. Nocturnal myoclonus. J Neurol Neurosurg Psychiatry 1953;16:166-71.

3 Lugaresi E, Coccagna G, Gambi D, Berti-Ceroni G, Poppi M. A propos de quelques manifestations nocturnes myocloniques (Nocturnal myoclonus de Symonds). Rev Neurol (Paris) 1966;115:547-55.

4 Coleman RM, Pollak CP, Weitzman ED. Periodic movements in sleep (nocturnal myoclonus): Relation to sleep disorders. Ann Neurol 1980;4:416-21.

5 Rosenthal L, Roehrs T, Sicklesteel J, Zorick F, Wittig R, Roth T. Periodic movements during sleep, sleep fragmentation, and sleep-wake complaints. Sleep 1984;7:326-30.

6 Saskin P, Moldofsky H, Lue FA. Periodic movements in sleep and sleep-wake complaints. Sleep 1985;8:319-24.

7 Ohanna N, Peled R, Rubin AE, Zomer J, Lavie P. Periodic leg movements in sleep: Effect of Clonazepam treatment. Neurology 1985;35:408-11.

8 Rechtschaffen A, Kales A, eds. A Manual of Standardized Terminology, Techniques and Scoring System for Sleep Stages of Human Subjects. Washington: US Government Printing Office, 1968.

9 Guilleminault C, Flagg W. Effect of Baclofen on sleeprelated periodic leg movements. Ann Neurol 1984;15: 234-9.

10 Guilleminault C, Raynal D, Weitzman ED, Dement WC. Sleep-related periodic myoclonus in patients complaining of insomnia. Trans Am Neurol Assoc 1975;100:19-21.

11 Moldofsky H, Tullis C, Quance G, Lue FA. Nitrazepam for insomnia or excessive somnolence associated with periodic movements in sleep (sleep-related myoclonus). Sleep Res 1985;14:191.

12 Kavey N, Hening W, Walters A, Gidro-Frank S, Cote L, Fahn S. Treatment of restless legs and periodic movements in sleep with opioids. Sleep Res 1985;14:177.

13 Coleman RM. Periodic movements in sleep (nocturnal myoclonus) and restless legs syndrome. In: Guilleminault C. ed. Sleeping and Waking Disorders: Indications and Techniques. Menlo Park, California: Addison-Wesley Publications, 1982;265-95.

14 Oshtory MA, Vijayan N. Clonazepam treatment of insomnia due to sleep myoclonus. Arch Neurol 1980;37:11.

15 Mitler MM, Browman CP, Menn SJ, Gujavarty K, Timms RM. Nocturnal myoclonus: treatment efficacy of clonazepam and temazepam. Sleep 1986;9:385-92. 